\title{
Synthesis of Carbon Nanotube/Silver Nanocomposites by Ultrasonication
}

\author{
Takahiro Yamada, Yamato Hayashi and Hirotsugu Takizawa \\ Department of Applied Chemistry, School of Engineering, Tohoku University, Sendai 980-8579, Japan
}

Carbon nanotube (CNT)/Ag nanocomposites were synthesized by an ultrasonic process. Dispersion of aggregated CNTs and synthesis of both $\mathrm{Ag}$ nanoparticles and $\mathrm{Ag} / \mathrm{CNT}$ composite particles were executed by ultrasonic treatment. Dispersibility of Ag nanoparticles improved with the combined use of a dispersant, which led to improved densification upon sintering. In addition, synthesis of nanosize Ag particles allowed sintering of the $\mathrm{CNT} / \mathrm{Ag}$ nanocomposites at $300^{\circ} \mathrm{C}$, with a resulting electrical resistivity of $2.46 \mu \Omega \cdot \mathrm{cm}$. [doi:10.2320/matertrans.MJ201012]

(Received April 1, 2010; Accepted July 29, 2010; Published September 8, 2010)

Keywords: ultrasonic, carbon nanotube, silver nanoparticles, nanocomposite

\section{Introduction}

Physicochemical properties of nanoparticles are unique in comparison to those of bulk materials because the total number of atoms is decreased and the specific surface area is increased. Ag has the highest electrical conductivity among the metals, and preparation of Ag materials, such as wiring, electrodes and contact materials, is attempted with lowtemperature sintering of nanoparticles due to the high surface energy of Ag nanoparticles. Ag nanoparticles are synthesized by various methods, such as thermal decomposition, chemical reduction, $\gamma$-irradiation, and ultrasonication. ${ }^{1-4)}$

Since the discovery of carbon nanotubes (CNTs) in 1991 by Iijima, ${ }^{5)}$ many scientists have studied their structure and properties. CNTs consist of single or multiple rolled layers of graphene and have high thermal conductivity and mechanical strength. CNT-reinforced nanocomposites have been developed for the purpose of functionalization of these properties. $^{6-10)}$ For the preparation of high functionality nanocomposites, it is necessary to disperse the CNTs by ultrasonication or mechanical mixing.

Ultrasonication generates cavitation bubbles in solution, which then collapse to produce shock waves and high temperature and pressure fields, known as hotspots. ${ }^{11)}$ Cleaning, admixtures and dispersion are increased by the physical effect of the shock wave. In addition, pyrolysis and radical reaction are caused at hotspots in solution, which can influence various chemical reactions. Some syntheses of metal nanoparticles by ultrasonication have been reported in the field of inorganic chemistry. Hayashi has reported that noble metal nanoparticles can be synthesized by ultrasonication of $\mathrm{Ag}_{2} \mathrm{O}, \mathrm{PdO}, \mathrm{PtO}_{2}, \mathrm{Au}_{2} \mathrm{O}_{3}$. ${ }^{12}$ )

Ag has high electrical conductivity and CNTs have high thermal conductivity and high mechanical strength; therefore, integration is expected to produce a composite material with the advantages of both. Such a material would have high thermal conductivity and durability, with possible applications in wiring, electrodes and contact materials. However, it is necessary to disperse the CNTs in the matrix for preparation of a dense sintered body. Ultrasonication is effective for both CNTs dispersion and synthesis of $\mathrm{Ag}$ nanoparticles. Therefore, in this paper ultrasonication was employed to disperse CNTs as the first step toward the

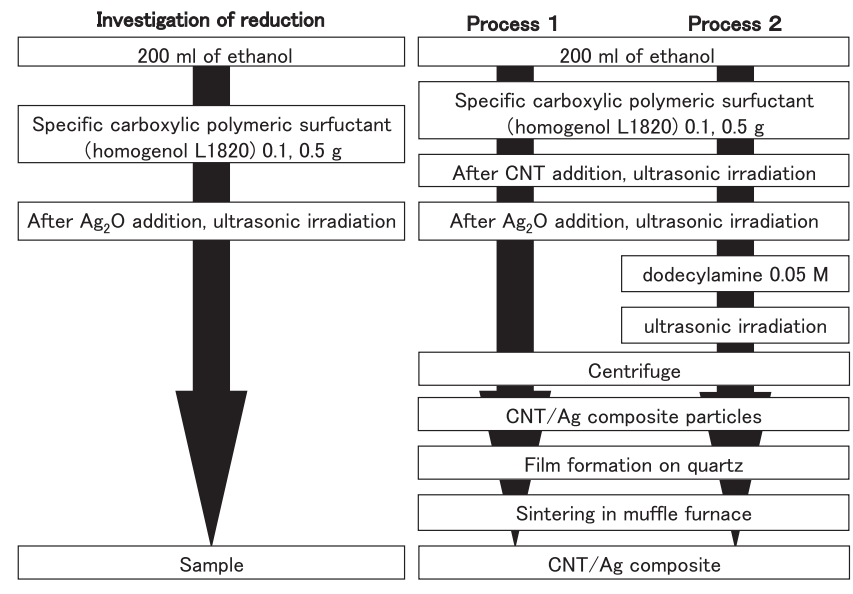

Fig. 1 Experimental procedure.

synthesis of the Ag/CNT composite particles. After sintering of the composite particles, electrical properties of $\mathrm{CNT} / \mathrm{Ag}$ nanocomposites were evaluated.

\section{Experimental}

\subsection{Materials and sonicator}

Silver oxide $\left(\mathrm{Ag}_{2} \mathrm{O}, 99 \%\right.$, Wako Pure Chemical Industries, Ltd.) was used as a silver source. Multi-walled carbon nanotubes (CNTs, Nikkiso Co. Ltd.) were used as received without further treatment. Ethanol $\left(\mathrm{C}_{2} \mathrm{H}_{5} \mathrm{OH}, 99.5 \%\right.$, Wako Pure Chemical Industries, Ltd.) was used as a solvent. A carboxylic polymeric surfactant (Homogenol L-1820, Kao Co., Ltd.) and dodecylamine $\left(\mathrm{C}_{12} \mathrm{H}_{25} \mathrm{NH}_{2}, 99 \%\right.$, Wako Pure Chemical Industries, Ltd.) were used as dispersants. Sonication (Digital Sonifier, Branson Co., Ltd.) was performed at a frequency of $20 \mathrm{kHz}$ by touching the tip of the sonicator horn to the solution.

\subsection{Experimental procedure}

\subsubsection{Investigation of $\mathrm{Ag}_{2} \mathrm{O}$ reduction to $\mathrm{Ag}$}

Figure 1 shows a schematic diagram of the experimental procedure. A solution was prepared by dissolving $0.5 \mathrm{~g}$ of surfactant (L-1820) in $200 \mathrm{~mL}$ of ethanol, $\mathrm{Ag}_{2} \mathrm{O}$ was added to this solution. This solution was ultrasonicated with $100 \mathrm{~W}$ and $20 \mathrm{kHz}$ for $60 \mathrm{~min}$ in pulse mode (repeated manipulation of ultrasonication for $1 \mathrm{~s}$ and rest for $1 \mathrm{~s}$ ). 


\subsubsection{Synthesis of CNT/Ag nanocomposite}

Figure 1 shows a diagram for the experimental procedure. A solution was prepared by dissolving 0.1 or $0.5 \mathrm{~g}$ of surfactant (L-1820) in $200 \mathrm{~mL}$ of ethanol, to which $0.0213 \mathrm{~g}$ of CNTs were added. To disperse the CNTs, the solution was ultrasonicated ( $100 \mathrm{~W}$ and $20 \mathrm{kHz}$ ) for $60 \mathrm{~min}$ in pulse mode. Subsequently, $4 \mathrm{~g}$ of $\mathrm{Ag}_{2} \mathrm{O}$ was added to this solution to provide a nominal composition of CNT $/ \mathrm{Ag}=3 \mathrm{vol} \%$, and the solution was ultrasonicated under the same conditions. This process was defined as Process 1. In Process 2, 0.05M of dodecylamine was added to the dispersion solution and ultrasonicated ( $100 \mathrm{~W}$ and $20 \mathrm{kHz}$ ) for $30 \mathrm{~min}$ in pulse mode.

The solutions were centrifuged to obtain $\mathrm{Ag} / \mathrm{CNT}$ composite particles. After scooping this deposit, films of these composite particles were prepared on a quartz substrate using a metal masking technique. The films were subsequently sintered in a muffle furnace at $300^{\circ} \mathrm{C}$ for $60 \mathrm{~min}$ to obtain sintered films. As a comparison, pure Ag films were prepared each process.

\subsection{Characterization}

Sample solutions were air-dried and the resulting powder samples were characterized using X-ray diffraction (XRD; Rigaku Rint 200). The microstructure and composition of the composite particles (and films) was observed using field emission scanning electron microscopy/energy dispersive Xray spectroscopy (FE-SEM/EDS; Jeol JSM-7000F); samples were prepared by dripping the sample solution onto $\mathrm{Cu}$ grids. The zeta potential was measured with a ZetasizerNano ZS (Malvern Instruments, ZEN3600). Thermogravimetry/differential thermal analysis (TG/DTA; TA Instruments, Japan SDT 2960) was performed to investigate the thermal response of samples. The electrical resistivity of the sintered films was measured using a Hall Effect measurement system (Bio-Rad HL 5500PC).

\section{Results and Discussion}

\subsection{Investigation of $\mathrm{Ag}_{2} \mathrm{O}$ reduction to $\mathrm{Ag}$}

Figure 2 shows XRD patterns of products obtained by ultrasonication of $\mathrm{Ag}_{2} \mathrm{O}$ for $60 \mathrm{~min}$. In the case of the sample without dispersant, the XRD pattern indicates incomplete reaction of $\mathrm{A}_{2} \mathrm{O}$ while $\mathrm{A}_{2} \mathrm{O}$ peaks are still present. However, the XRD pattern of the product with the L-1820 surfactant indicates the complete reaction of $\mathrm{A}_{2} \mathrm{O}$; therefore, $\mathrm{L}-1820$ promotes reaction from $\mathrm{Ag}_{2} \mathrm{O}$ to $\mathrm{Ag}$ and shortens the reaction time. As a key factor of this phenomenon, reducible surfactant may relate to the reduction of $\mathrm{Ag}_{2} \mathrm{O}$. It seems that $\mathrm{L}-1820$ as reducible surfactant promotes reduction of $\mathrm{Ag}_{2} \mathrm{O}$ in this system, because L-1820 with carboxyl group works as a reducing agent.

\subsection{Synthesis of CNT/Ag nanocomposite}

Figure 3 shows XRD patterns of the CNT and $\mathrm{Ag}_{2} \mathrm{O}$ raw materials, and the products from each process. The product from process 1 consists of $\mathrm{Ag}$ and $\mathrm{CH}_{3} \mathrm{COOAg}$, and completely reacted from $\mathrm{Ag}_{2} \mathrm{O}$ after ultrasonic irradiation for $60 \mathrm{~min}$. No peak of CNT was observed, because the volume ratio of CNTs to Ag was low. The mechanism for $\mathrm{CH}_{3} \mathrm{COOAg}$ generation is considered to be as follows.

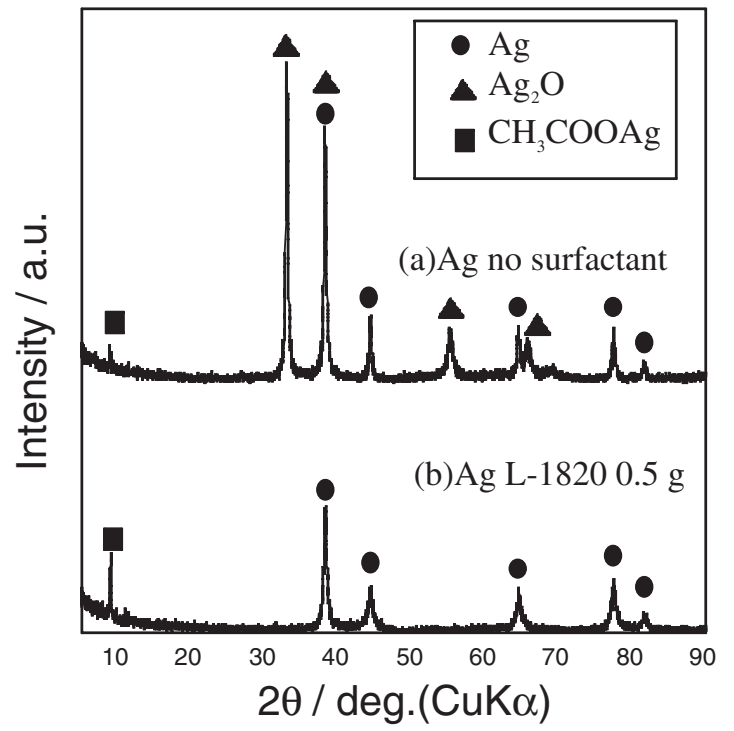

Fig. 2 XRD patterns of products obtained by ultrasonication of $\mathrm{Ag}_{2} \mathrm{O}$ for $60 \mathrm{~min}$.

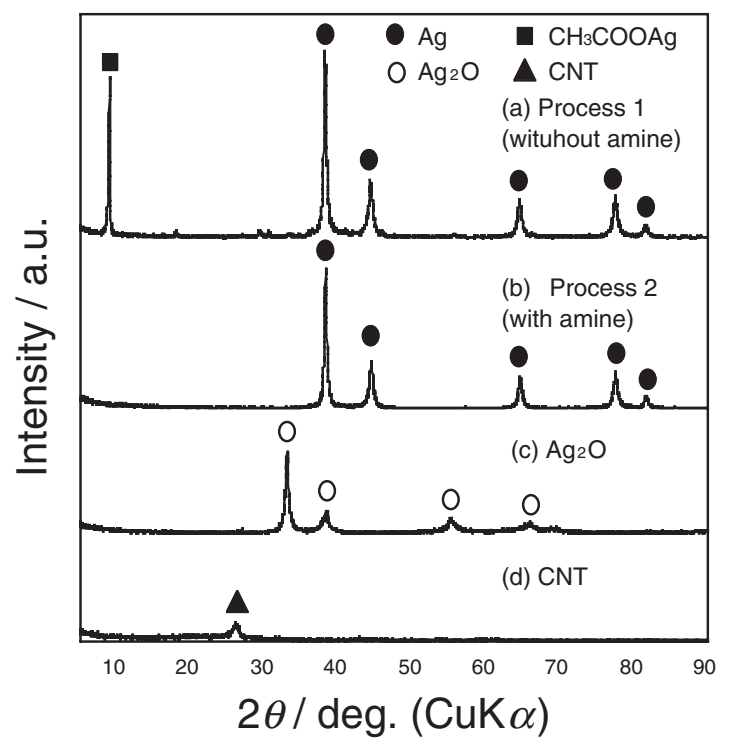

Fig. 3 XRD patterns of the raw materials and the products from each process.

Ethanol is oxidized to produce acetic acid through an unstable acetaldehyde intermediate. The acetic acid then undergoes radical reaction by ultrasonication to generate carboxyl radicals. ${ }^{13)}$ Finally, $\mathrm{CH}_{3} \mathrm{COOAg}$ is generated by the reaction of carboxyl radicals and $\mathrm{Ag}_{2} \mathrm{O}$. The $\mathrm{CH}_{3} \mathrm{COOAg}$ peak disappears and only Ag peaks are confirmed in the XRD pattern of the product from process 2 . This is because $\mathrm{Ag}$ is generated by the reaction of $\mathrm{CH}_{3} \mathrm{COOAg}$ and the dodecylamine. Hiramatsu et al. reported that Ag nanoparticles were synthesized by reaction of oleylamine and silver acetate. ${ }^{14)}$ They considered that the carbon double bond of oleylamine did not play an important role in this reaction, because the same reaction resulted when using an aliphatic amine such as dodecylamine. Therefore, in this system it is considered that Ag nanoparticles are produced by the reaction of dodecylamine and silver acetate. 
Figure 4 shows a FE-SEM image of an ultrasonicated CNT sample with L-1820 as dispersant. The dispersant functions well and there are few aggregations present. It is estimated that physical effect of shock wave and protection of CNT by L-1820 lead to CNTs dispersion. Also, the zeta potential of this sample is $-50 \mathrm{mV}$. Figure 5 shows FE-SEM images of CNT/Ag composite particles. Nanoparticles of approximately $50 \mathrm{~nm}$ are supported on the CNT surface. EDS analysis confirmed that these nanoparticles were Ag. Also, amount of Ag nanoparticles supported on CNT surface increase with amount of L-1820. Kim et al. reported that $\mathrm{Au}$ nanoparticles were supported on a CNT surface coated by a polyelectrolyte using electrical attractive force. ${ }^{15)}$ Yang et al. reported that CNT surface were modified by polyvinyl alcohol, and $\mathrm{Al}^{3+}$ ions adsorbed on the surface with electrical attractive force. As a result, $\mathrm{Al}(\mathrm{OH})_{3}$ deposited on the surface. ${ }^{16)}$ In the present system, CNT surface coated by $\mathrm{L}-1820$, and $\mathrm{Ag}^{+}$ions or $\mathrm{Ag}$ clusters adsorb on the surface with electrical attractive force, which leads to the preparation of $\mathrm{Ag}$ nanoparticles.

The microstructure of the products was examined to investigate the difference between each process. Figure 6

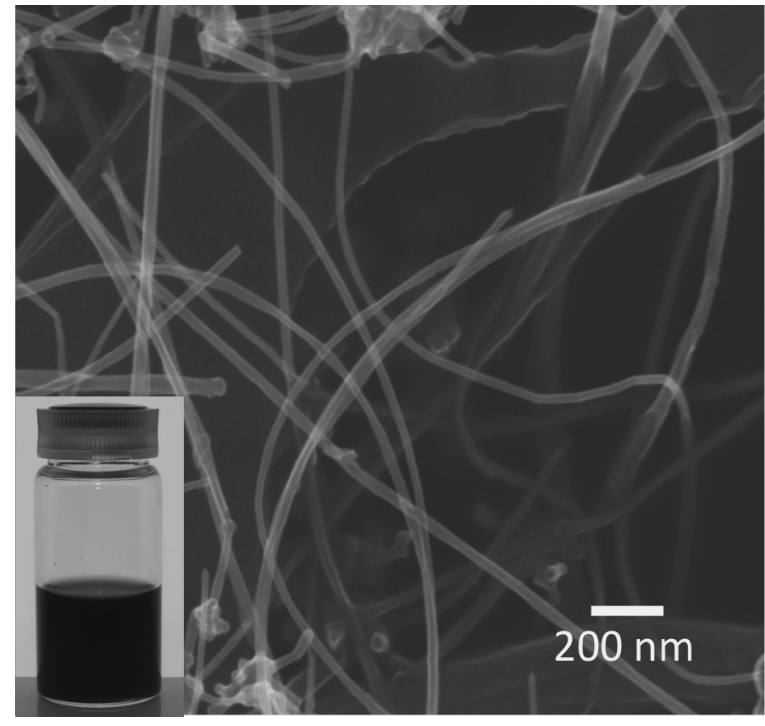

Fig. 4 FE-SEM image of an ultrasonicated sample with CNTs and L-1820 as dispersant after ultrasonic irradiation for $60 \mathrm{~min}$.
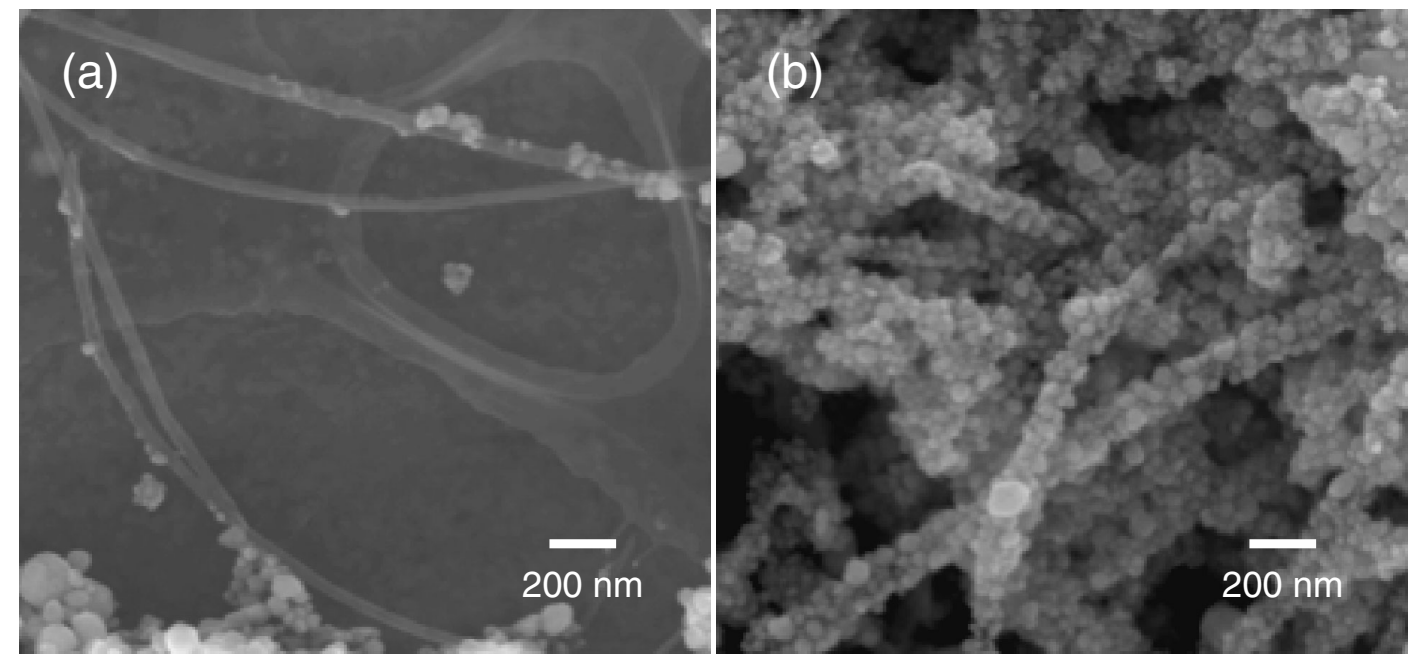

Fig. 5 FE-SEM images of CNT/Ag composite particles with L-1820 of (a) $0.1 \mathrm{~g}$, (b) $0.5 \mathrm{~g}$.

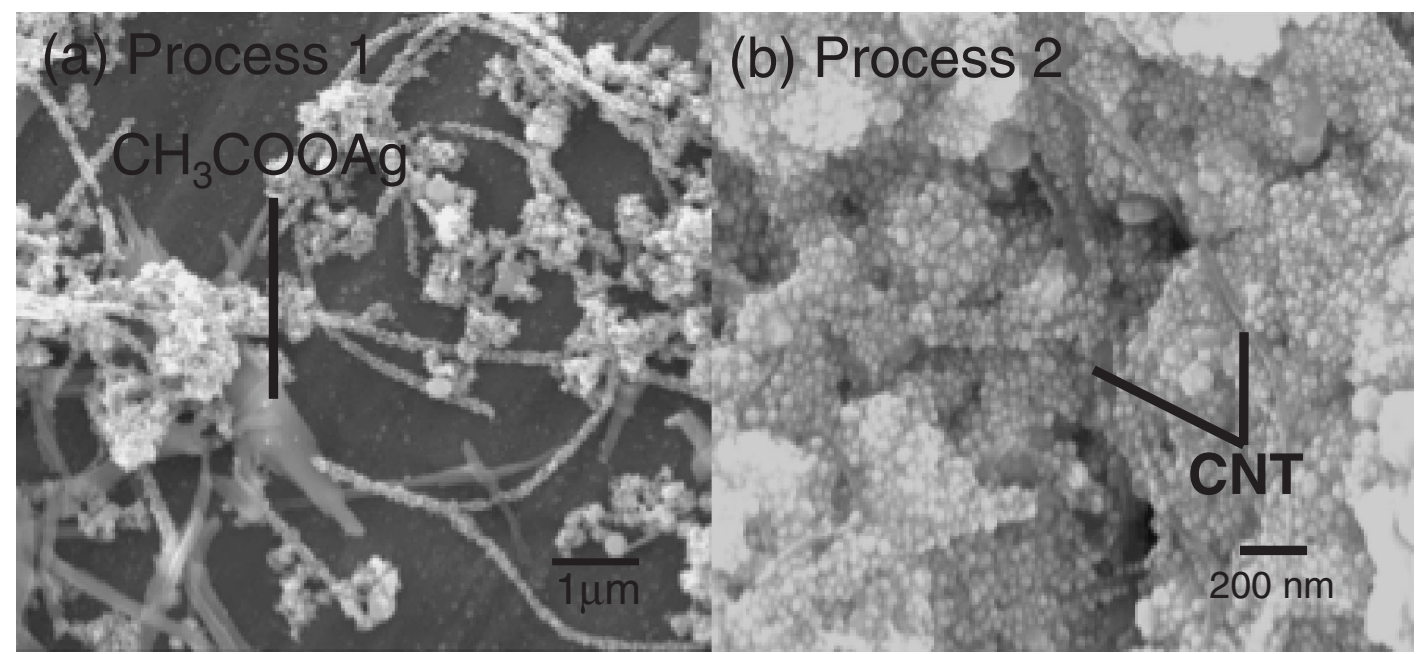

Fig. 6 FE-SEM images of composite particles prepared by each process. (a) Process 1 (without amine), (b) Process 2 (with amine). 


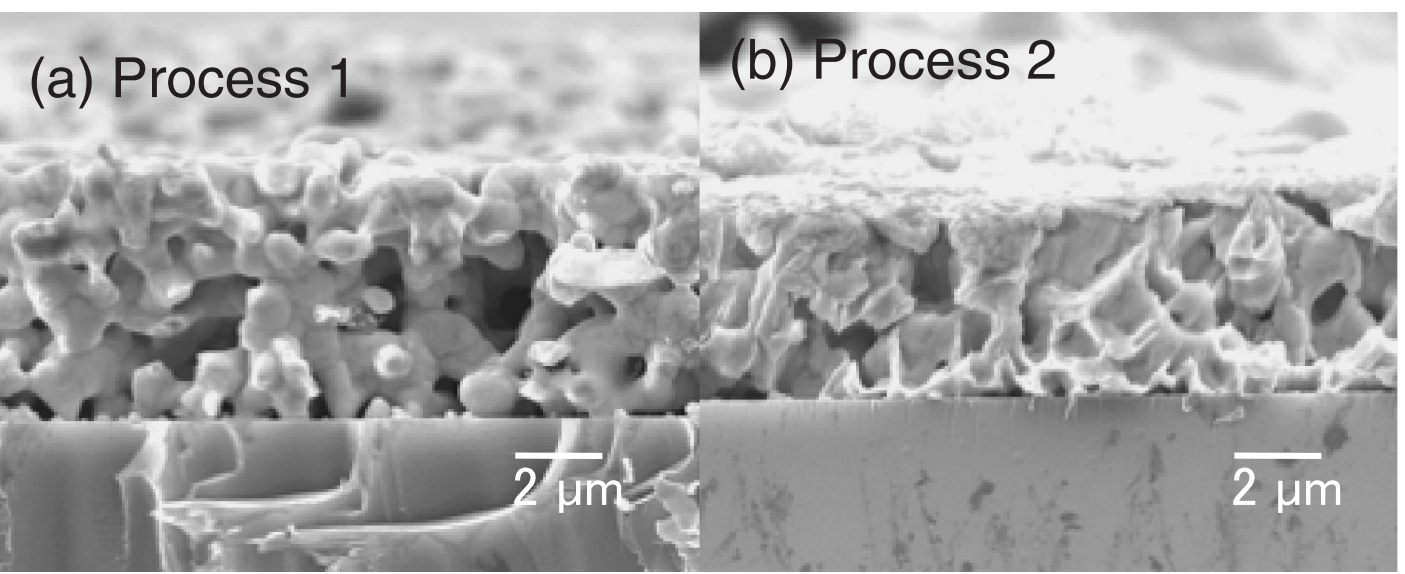

Fig. 7 FE-SEM images of the samples that sinter composite particles prepared in each process at $300^{\circ} \mathrm{C}$ for 60 min. (a) Process 1 (without amine), (b) Process 2 (with amine).

shows FE-SEM images of the composite particles prepared by each process. The sample made by process 1 contains $\mathrm{Ag}$ and $\mathrm{CH}_{3} \mathrm{COOAg}$, as confirmed by XRD analysis. The sample prepared by process 2 has a comparatively uniform array of $\mathrm{Ag}$ nanoparticles. The effect of dodecylamine addition in process 2 is considered to be as follows. Dodecylamine promotes the reaction of $\mathrm{CH}_{3} \mathrm{COOAg}$ to $\mathrm{Ag}$ and protects the surface of $\mathrm{Ag}$ nanoparticles by preventing agglomeration growth.

TG-DTA analysis indicated the resolution of organic substance at $300^{\circ} \mathrm{C}$, because there was no weight loss at temperatures higher than $300^{\circ} \mathrm{C}$. Therefore, the sintered films were prepared at $300^{\circ} \mathrm{C}$. Figure 7 shows FE-SEM images of the films of sintered composite particles prepared by each process. The sample prepared by process 2 had a denser microstructure than that prepared by process 1 . The comparatively uniform array of $\mathrm{Ag}$ nanoparticles shown in Fig. 6(b) may contribute to a denser sintered film. In addition, the electrical resistivities of the samples prepared by processes 1 and 2 were 7.61 and $2.46 \mu \Omega \cdot \mathrm{cm}$, respectively, which was consistent with the microstructural densities observed. Also, the electrical resistivities of $\mathrm{Ag}$ films prepared each process were similar extent.

\section{Conclusion}

The synthesis of a CNT/silver nanoparticle composite by ultrasonication was reported. Synthesis of $\mathrm{Ag}$ nanoparticles enabled the sintering of $\mathrm{CNT} / \mathrm{Ag}$ nanocomposites at $300^{\circ} \mathrm{C}$. Densification of the sintered films was investigated using two different preparation processes for improvement of the electrical conductivity. Dispersion of CNTs and synthesis of
Ag nanoparticles were possible by combination ultrasonic treatment and use of organic dispersant, and it was confirmed that the organic dispersant acts as a reducing agent. Therefore, it is useful for the synthesis of CNT/Ag nanocomposites by ultrasonication.

\section{REFERENCES}

1) M. Chen, Y. G. Feng, X. Wang, T. C. Li, J. Y. Zhang and D. J. Qian: Langmuir 23 (2007) 5296-5304.

2) D. H. Chen and Y. W. Huang: J. Colloid Interface Sci. 255 (2002) 299-302.

3) A. Henglein, P. Mulvaney and T. Linnert: Electrochem. Acta 36 (1991) 1743-1745.

4) M. Zheng, Z. S. Wang and Y. W. Zhu: Trans. Nonferrous Met. Soc. China 16 (2006) 1348-1352.

5) S. Iijima: Nature 354 (1991) 56.

6) A. K. Keshri, J. Huang, V. Singh, W. Choi, S. Seal and A. Agarwal: Carbon 48 (2010) 431-442.

7) L. Wang, H. Choi, J. M. Myoung and W. Lee: Carbon 47 (2009) 34273433.

8) W. M. Daush, B. K. Lim, C. B. Mo, D. H. Nam and S. H. Hong: Mater. Sci. Eng. A 513-514 (2009) 247-253.

9) H. Kwon, M. Estilli, K. Takagi, T. Miyazaki and A. Kawasaki: Carbon 47 (2009) 570-577.

10) F. Lupo, R. Kamalakaran, C. Sheu, N. Grobert and M. Rühle: Carbon 42 (2004) 1995-1999.

11) K. S. Suslick: Annu. Rev. Mater. Sci. 29 (1999) 295.

12) Y. Hayashi, H. Takizawa, M. Inoue, K. Niihara and K. Suganuma: IEEE Trans. Elect. Manufact. 28 (2005) 338-343.

13) T. Kimura, H. Harada, T. Ando, M. Fujita, J. M. Levêque and J. L. Luche: Chem. Commun. 11 (2002) 1174-1175.

14) H. Hiramatsu and F. E. Osterloh: Chem. Mater. 13 (2004) 25092511.

15) B. Kim and W. M. Sigmund: Langmuir 20 (2004) 8239-8242.

16) Q. Yang, Y. Deng and W. Hu: Ceram. Int. 35 (2009) 1305-1310. 